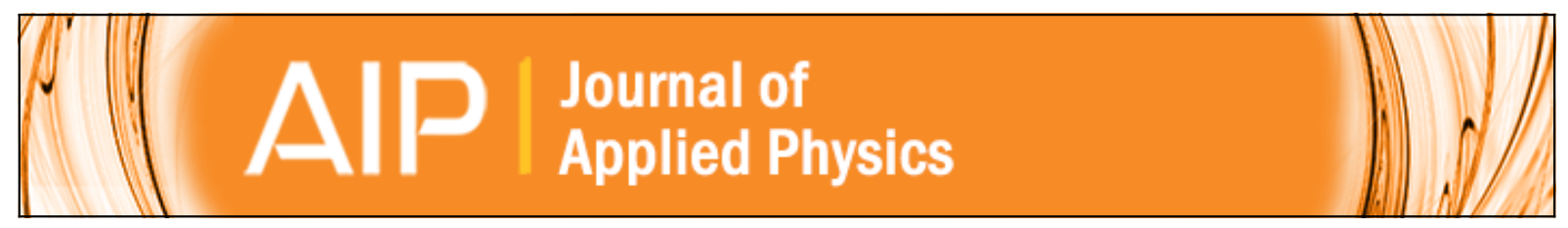

\title{
Photoluminescence from Si nanocrystals exposed to a hydrogen plasma
}

Yoon-Jin Jung, Jong-Hwan Yoon, R. G. Elliman, and A. R. Wilkinson

Citation: Journal of Applied Physics 104, 083518 (2008); doi: 10.1063/1.3002913

View online: http://dx.doi.org/10.1063/1.3002913

View Table of Contents: http://scitation.aip.org/content/aip/journal/jap/104/8?ver=pdfcov

Published by the AIP Publishing

\section{Articles you may be interested in}

Structural and optical properties of size controlled Si nanocrystals in Si3N4 matrix: The nature of photoluminescence peak shift

J. Appl. Phys. 114, 184311 (2013); 10.1063/1.4830026

Effect of hydrogenation on the memory properties of Si nanocrystals obtained by inductively coupled plasma chemical vapor deposition

Appl. Phys. Lett. 89, 202112 (2006); 10.1063/1.2388144

$\mathrm{H}$-induced effects in luminescent silicon nanostructures obtained from plasma enhanced chemical vapor deposition grown Si y O $1-\mathrm{y}: \mathrm{H}(\mathrm{y}>1 / 3)$ thin films annealed in $(\mathrm{Ar}+5 \% \mathrm{H} 2)$

J. Vac. Sci. Technol. A 24, 817 (2006); 10.1116/1.2177227

Effect of nitride passivation on the visible photoluminescence from Si-nanocrystals

Appl. Phys. Lett. 85, 3408 (2004); 10.1063/1.1787599

Getting high-efficiency photoluminescence from Si nanocrystals in SiO 2 matrix Appl. Phys. Lett. 81, 4174 (2002); 10.1063/1.1525395
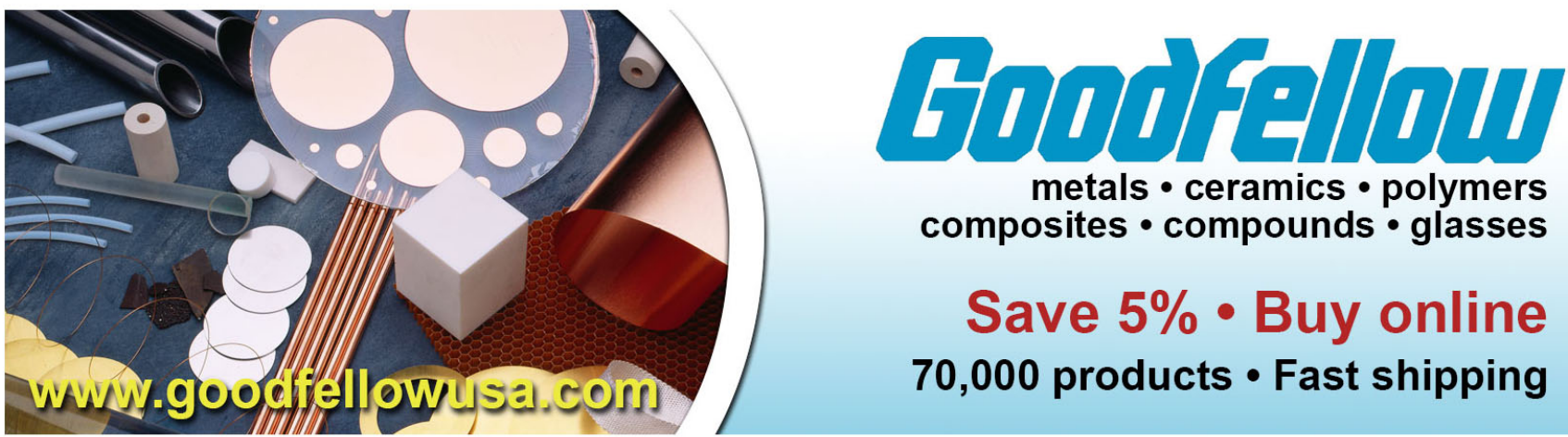


\title{
Photoluminescence from Si nanocrystals exposed to a hydrogen plasma
}

\author{
Yoon-Jin Jung, ${ }^{1}$ Jong-Hwan Yoon, ${ }^{1, a)}$ R. G. Elliman, ${ }^{2}$ and A. R. Wilkinson ${ }^{2}$ \\ ${ }^{1}$ Department of Physics, College of Natural Sciences, Kangwon National University, Chuncheon, Kangwon- \\ do 200-701, Republic of Korea \\ ${ }^{2}$ Department of Electronic Materials Engineering, Research School of Physical Sciences and Engineering, \\ The Australian National University, Canberra, ACT 0200, Australia
}

(Received 23 June 2008; accepted 2 September 2008; published online 28 October 2008)

\begin{abstract}
$\mathrm{Si}$ nanocrystals embedded in $\mathrm{SiO}_{2}$ films were exposed to an atomic $\mathrm{H}$ plasma at different temperatures. Photoluminescence intensity from the nanocrystals increases with increasing exposure time, followed by saturation that depends on the exposure temperature. The saturation level depends on the final exposure temperature and shows no dependence on the thermal history of exposure. This behavior is shown to be consistent with a model in which the steady-state passivation level is determined by a balance between defect passivation and depassivation by $\mathrm{H}$, with the activation energy for the passivation reaction being larger than that for the depassivation reaction. (C) 2008 American Institute of Physics. [DOI: 10.1063/1.3002913]
\end{abstract}

\section{INTRODUCTION}

Visible light emission from Si nanocrystals embedded in a $\mathrm{SiO}_{2}$ matrix has received much attention because of the potential for optoelectronic applications. However, despite extensive studies on the light emission from Si nanocrystals, the origin of visible luminescence has so far been unclear.

The mechanisms for the visible luminescence from $\mathrm{Si}$ nanocrystals can be classified into two categories: the quantum confinement and the defect-related luminescence. ${ }^{1,2}$ The former is caused by band-to-band recombination of excitons confined in $\mathrm{Si}$ nanocrystals less than $5 \mathrm{~nm}$ (exciton Bohr radius). In this case, the luminescence energy is strongly dependent on the size of Si nanocrystals, while the latter is attributable to defects at $\mathrm{Si}$ nanocrystal/ $/ \mathrm{SiO}_{2}$ interface. Considerable effort has been made to understand the character of defects at the $\mathrm{Si} / \mathrm{SiO}_{2}$ interface. A large body of $\mathrm{H}$ passivation in $\mathrm{Si} / \mathrm{SiO}_{2}$ structural materials has been reported. ${ }^{3-8} \mathrm{H}$ passivation is generally shown to result in an increase in the photoluminescence (PL) intensity. ${ }^{1-5}$ Furthermore, it has been suggested that the $\mathrm{H}$-passivation-induced increase in PL intensity in the $\mathrm{Si}$ nanocrystal/ $/ \mathrm{SiO}_{2}$ structures is caused by passivation of the defects at $\mathrm{Si}$ nanocrystal/ $/ \mathrm{SiO}_{2}$ interface. ${ }^{9,10}$ However, there is still a possibility that the H-passivationenhanced PL intensity can also be caused by an increase in the density of Si nanocrystals.

In this work, we have studied the effects of atomic $\mathrm{H}$ passivation on the PL and microstructure of $\mathrm{SiO}_{2}$ films containing Si nanocrystals. The passivation was performed by directly exposing the films to an atomic hydrogen plasma generated within a plasma-enhanced chemical vapor deposition (PECVD) system. Atomic $\mathrm{H}$ exposure is shown to result in an increase in the PL intensity, eventually followed by saturation, which is strongly dependent on the substrate temperature, without changing the size and density of Si nanocrystals. This provides an evidence that the H-passivationenhanced PL intensity is not due to an increase in the density

${ }^{a)}$ Electronic mail: jhyoon@kangwon.ac.kr. of Si nanocrystals. A possible suggestion has been made for the H-passivation-enhanced $\mathrm{PL}$ intensity from $\mathrm{SiO}_{2}$ containing Si nanocrystals.

\section{EXPERIMENTS}

$\mathrm{SiO}_{2}$ films containing $\mathrm{Si}$ nanocrystals were prepared by thermally annealing $\mathrm{Si}$-rich oxide $\left(\mathrm{SiO}_{x}\right)$ films. Films of approximately $200 \mathrm{~nm}$ thickness were deposited onto (100) oriented Czochralski Si wafers held at a temperature of $300{ }^{\circ} \mathrm{C}$ by PECVD using fixed flow rates of $\mathrm{SiH}_{4}$ (160 SCCM) (SCCM denotes cubic centimeter per minute at STP) and $\mathrm{N}_{2} \mathrm{O}$ (50 SCCM). The films had a composition of $\mathrm{SiO}_{1.16}$ and were subsequently annealed at $1100{ }^{\circ} \mathrm{C}$ for $1 \mathrm{~h}$ in a quartztube furnace using flowing high purity $\mathrm{N}_{2}$ gas $(99.999 \%)$ as an environment to precipitate the Si nanocrystals.

Atomic $\mathrm{H}$ exposure was performed by exposing the films to an atomic $\mathrm{H}$ plasma produced between two capacitively coupled disk electrodes using a rf power of $290 \mathrm{~mW} / \mathrm{cm}^{2}$ (13.56 $\mathrm{MHz}$ frequency) and pure $\mathrm{H}_{2}$ gas $(99.999 \%)$. The sample was placed on the bottom electrode, which was heated to an elevated temperature. The pressure and flow rate of $\mathrm{H}_{2}$ gas in the PECVD reactor during $\mathrm{H}$ exposure were 1 Torr and 180 SCCM, respectively.

The microstructure of $\mathrm{SiO}_{2}$ films containing Si nanocrystals was investigated by transmission electron microscopy (TEM) using a JEOL JEM 2010 instrument operating at 200 $\mathrm{kV}$. PL measurements were performed at room temperature using the $488 \mathrm{~nm}$ line of an $\mathrm{Ar}^{+}$laser as the excitation source. Emitted light was analyzed using a single-grating monochromator and detected with a thermoelectrically cooled charge-coupled device array (Andor DU401). All spectra were corrected for the system response. Timeresolved PL measurements were also performed by modulating the laser beam with an acoustic-optic modulator (Brimrose TEM-85-10). ${ }^{11}$ Emission decay lifetimes were extracted by the least-squares fitting of a stretched exponential. 


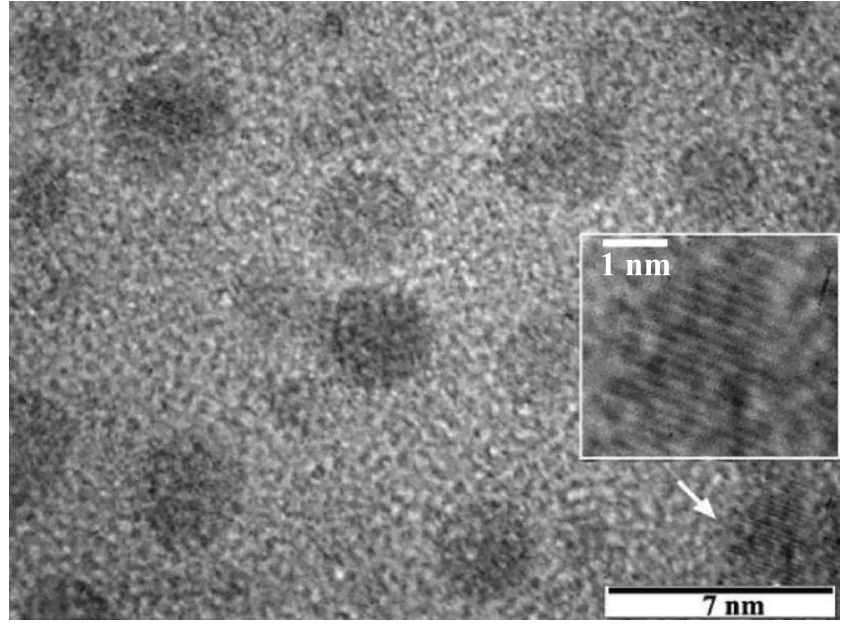

FIG. 1. High-resolution plane-view TEM image of Si nanocrystals in $\mathrm{SiO}_{2}$ produced by annealing a $\mathrm{SiO}_{1.16}$ film at $1100{ }^{\circ} \mathrm{C}$ for $1 \mathrm{~h}$. Dark spots represent $\mathrm{Si}$ nanocrystals. The inset is the high magnification of the Si nanocrystal marked with a white arrow.

\section{RESULTS AND DISCUSSION}

Figure 1 shows a plane-view high resolution TEM image of a $\mathrm{SiO}_{1.16}$ film annealed at $1100{ }^{\circ} \mathrm{C}$ for $1 \mathrm{~h}$. The TEM image clearly shows the presence of $\mathrm{Si}$ nanocrystals with well-defined boundaries and approximately spherical shape within the $\mathrm{SiO}_{2}$ matrix. The detailed microstructure of the nanocrystals marked with a white arrow (inset) reveals a regular lattice structure consistent with it being a single crystal phase. The average size (diameter) and areal density of the nanocrystals were about $2.8 \mathrm{~nm}$ and $4.3 \times 10^{12} \mathrm{~cm}^{-2}$, respectively. The standard deviation for the size distribution was about $0.17 \mathrm{~nm}$. According to the quantum confinement effect, such a size distribution should lead to a PL spectrum peaked at $620 \mathrm{~nm} .^{12}$

Figure 2 shows the PL spectrum of the sample shown in Fig. 1 together with that of an as-grown sample (not annealed) for comparison. The dotted curve represents the PL spectrum of the as-grown sample. The PL of the as-grown sample reveals an asymmetrical band with a peak around 580

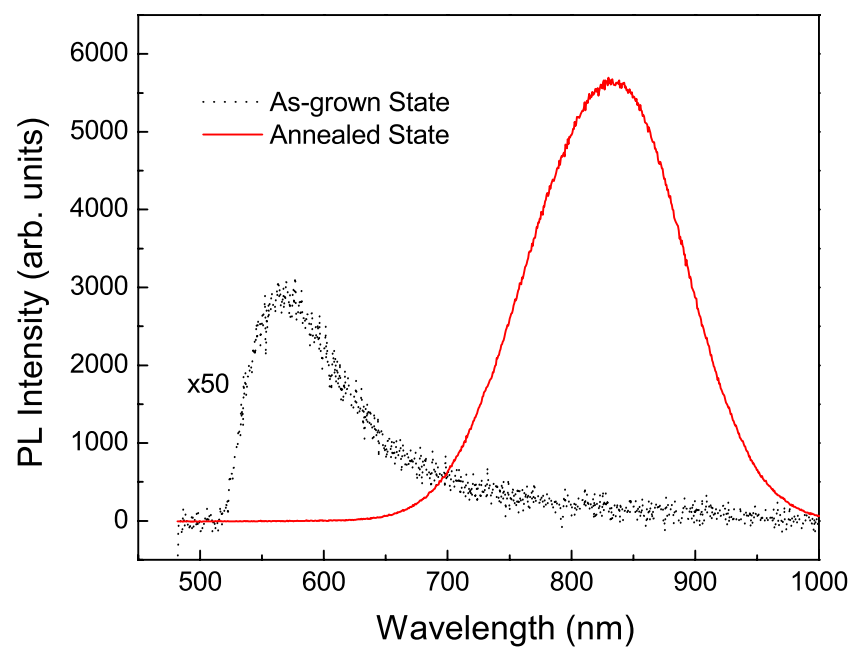

FIG. 2. (Color online) Room temperature PL spectra of $\mathrm{SiO}_{1.16}$ films asgrown (dotted curve) and annealed at $1100{ }^{\circ} \mathrm{C}$ for $1 \mathrm{~h}$ (solid curve).

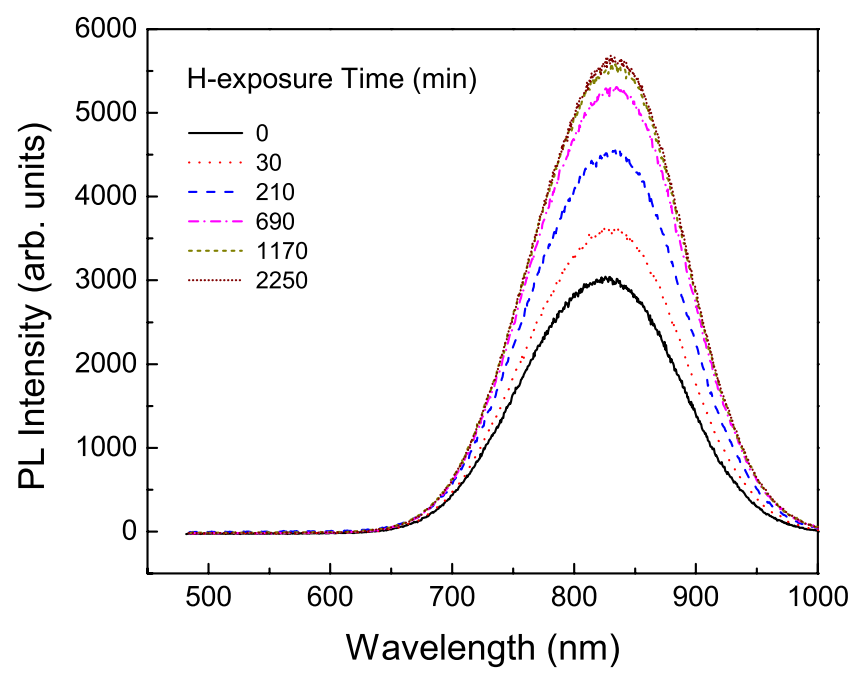

FIG. 3. (Color online) Room temperature PL spectra of $\mathrm{SiO}_{1.16}$ films annealed at $1100{ }^{\circ} \mathrm{C}$ for $1 \mathrm{~h}$ with subsequent exposure to an atomic $\mathrm{H}$ plasma at $250{ }^{\circ} \mathrm{C}$ for different times.

$\mathrm{nm}(2.2 \mathrm{eV})$, which is in agreement with that widely observed in $\mathrm{SiO}_{2}$ and is believed to result from the native defects in the matrix. ${ }^{13-15}$ On the other hand, the PL of annealed state shows a broad and symmetric band with a peak around $830 \mathrm{~nm}(1.5 \mathrm{eV})$ and a full width at half maximum of $150 \mathrm{~nm}$. This PL spectrum is also well consistent with those widely observed for $\mathrm{Si}$ nanocrystals embedded in $\mathrm{SiO}_{2}$ matrix. ${ }^{2,9,13}$ Note that the PL peak of annealed state is much different from that of as-grown state (due to matrix defects). Furthermore, the PL peak also differs from that due to the quantum confinement mechanism in the Si nanocrystals with the average size shown in Fig. 1. The present results provide an implication that the PL from $\mathrm{SiO}_{2}$ containing Si nanocrystals is closely associated with other factors formed during the formation of the nanocrystals, probably defects at $\mathrm{Si}$ nanocrystal/ $\mathrm{SiO}_{2}$ interface. Many previous studies ${ }^{2,9-11}$ suggested that defects at $\mathrm{Si}$ nanocrystal $/ \mathrm{SiO}_{2}$ interface play a crucial role in light emission from Si nanocrystal embedded in $\mathrm{SiO}_{2}$ matrix.

Figure 3 shows the PL spectra of the sample shown in Fig. 1 exposed to $\mathrm{H}$ plasma at $250{ }^{\circ} \mathrm{C}$ for different periods of time. It is evident that the PL intensity increases with the increasing $\mathrm{H}$-exposing time and seems to saturate for extended $\mathrm{H}$-exposing time. The details of an increase in the PL following $\mathrm{H}$ exposure will be presented and discussed in Fig. 6. An increase in the PL intensity due to $\mathrm{H}$ passivation can result to either the passivation of luminescence-quenching defects at $\mathrm{Si}$ nanocrystals $/ \mathrm{SiO}_{2}$ interface or an increase in the density of luminescent Si nanocrystals. However, the results shown in Figs. 4 and 5 support the premise that the latter is unlikely for the present result.

Figure 4 shows a plane-view high resolution TEM image of the sample passivated with $\mathrm{H}$. The passivation was performed by exposing the same sample as shown in Fig. 1 to an atomic $\mathrm{H}$ plasma at $250{ }^{\circ} \mathrm{C}$ for $2250 \mathrm{~min}$. As estimated using the TEM image, the average diameter and areal density of the Si nanocrystals were $2.8 \mathrm{~nm}$ and $4.4 \times 10^{12} \mathrm{~cm}^{-2}$, respectively, very similar to those of unpassivated state shown in Fig. 1. These results strongly suggest that H-passivation- 


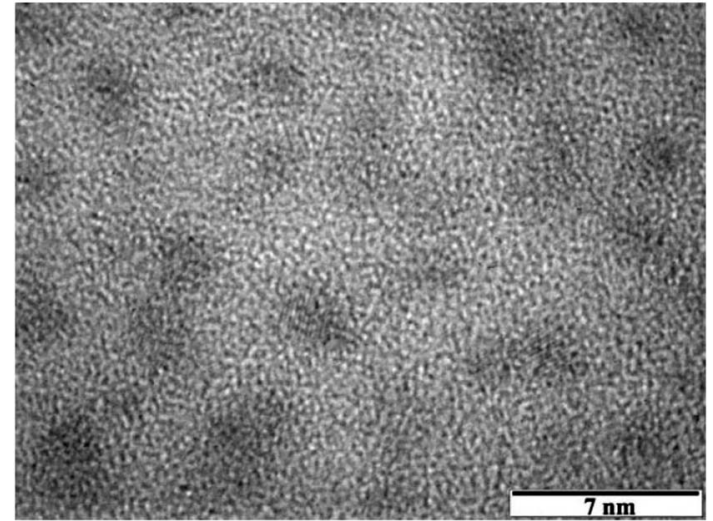

FIG. 4. High-resolution plane-view TEM image of $\mathrm{Si}$ nanocrystals in $\mathrm{SiO}_{2}$ produced by annealing a $\mathrm{SiO}_{1.16}$ film at $1100{ }^{\circ} \mathrm{C}$ for $1 \mathrm{~h}$ with subsequent $\mathrm{H}$ plasma exposure at $250{ }^{\circ} \mathrm{C}$ for $2250 \mathrm{~min}$. Dark spots represent $\mathrm{Si}$ nanocrystals.

enhanced PL intensity does not result from an increase in the density of Si nanocrystals from $\mathrm{H}$ passivation. Further support of this suggestion is shown in Fig. 5, which compares the PL spectra of unpassivated, passivated, and depassivated states of the sample shown in Fig. 1. The sample was passivated at $250{ }^{\circ} \mathrm{C}$ for $2250 \mathrm{~min}$ and subsequently depassivated by thermal annealing at $800{ }^{\circ} \mathrm{C}$ for $1 \mathrm{~h}$. The PL intensity is clearly shown to be fully recovered by depassivation without changing the PL shape, including the PL peak energy. This also confirms that the H-passivation-enhanced PL is unlikely associated with an increase in the density of the nanocrystals because it would not be expected that $\mathrm{Si}$ nanocrystals are annihilated by thermal annealing. As a result, it is suggested that the visible $\mathrm{PL}$ from $\mathrm{SiO}_{2}$ containing $\mathrm{Si}$ nanocrystals is closely associated with defects at $\mathrm{Si}$ nanocrystal $/ \mathrm{SiO}_{2}$ interface created during the formation of Si nanocrystals.

Figure 6 shows the PL peak intensity from $\mathrm{SiO}_{2}$ containing $\mathrm{Si}$ nanocrystals produced by annealing $\mathrm{SiO}_{1.16}$ film at $1100{ }^{\circ} \mathrm{C}$ for $1 \mathrm{~h}$ with subsequent $\mathrm{H}$ exposure as a function of exposure time for different exposure temperatures. The PL

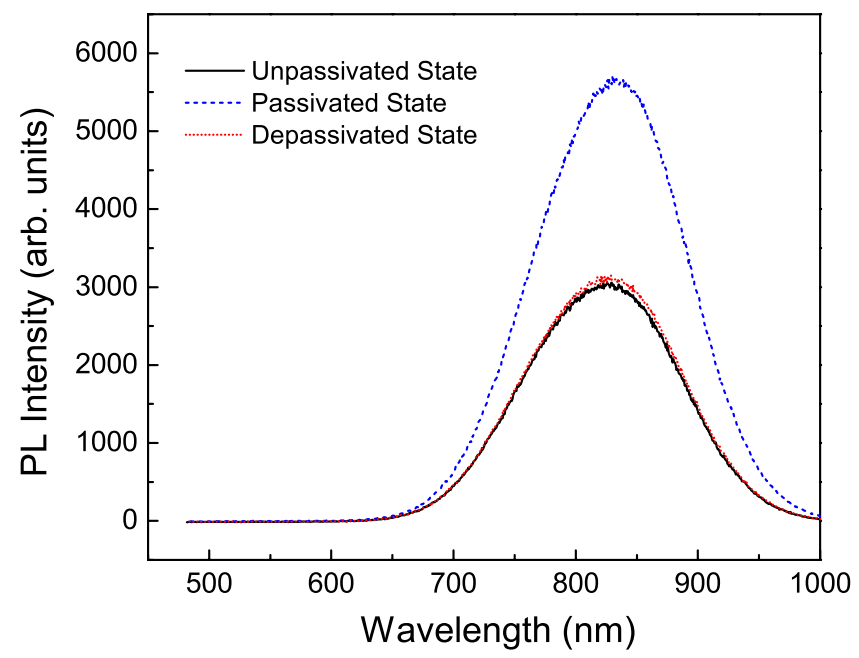

FIG. 5. (Color online) $\mathrm{PL}$ spectra of $\mathrm{SiO}_{1.16}$ films annealed at $1100{ }^{\circ} \mathrm{C}$ for 1 $\mathrm{h}$ for unpassivated (as-annealed), passivated (exposed to $\mathrm{H}$ plasma at $250{ }^{\circ} \mathrm{C}$ for $2250 \mathrm{~min}$ ), and depassivated (exposed to $\mathrm{H}$ plasma at $250{ }^{\circ} \mathrm{C}$ for $2250 \mathrm{~min}$ and subsequently furnace annealed at $800{ }^{\circ} \mathrm{C}$ for $1 \mathrm{~h}$ ) states.

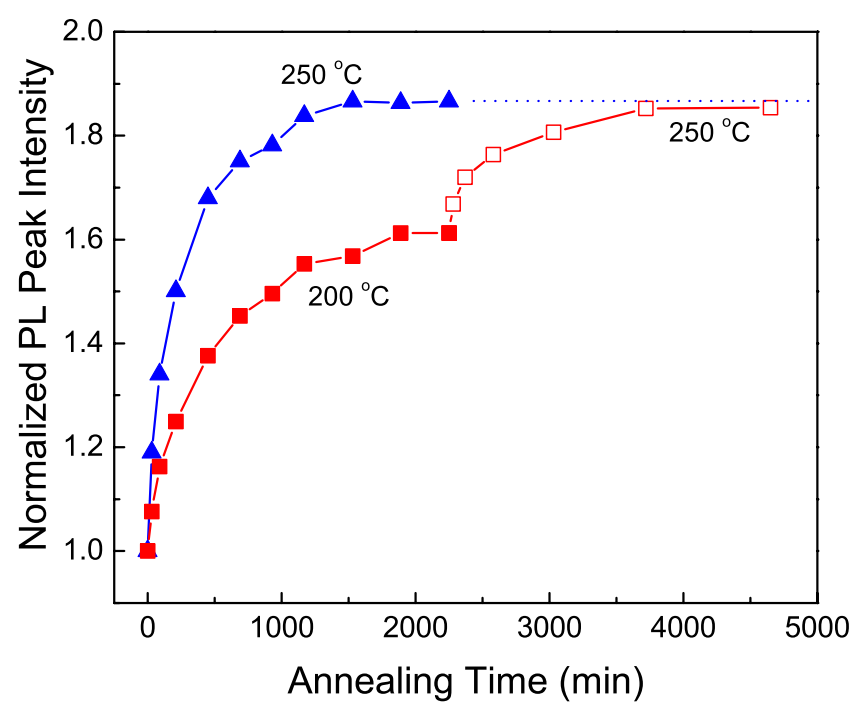

FIG. 6. (Color online) Normalized peak PL intensity of $\mathrm{SiO}_{1.16}$ film annealed at $1100{ }^{\circ} \mathrm{C}$ for $1 \mathrm{~h}$ with subsequent $\mathrm{H}$ plasma exposure as a function of exposure time for different exposure temperatures.

peak intensities were normalized to the initial (unpassivated) value. This compares the PL peak intensity as a function of exposure time for a sample held at $250{ }^{\circ} \mathrm{C}$ with that of a sample heated to $200{ }^{\circ} \mathrm{C}$ and subsequently heated to $250{ }^{\circ} \mathrm{C}$. The PL peak intensity increases with the increasing $\mathrm{H}$-exposing time, eventually followed by saturation. The additional high-temperature exposure is clearly shown to increase the PL intensity to a new saturation value that is equivalent to that of the sample heated directly to $250{ }^{\circ} \mathrm{C}$. This demonstrates that the saturation level is strongly dependent on temperature, with the saturation intensity increasing with the increasing temperature. Furthermore, this confirms that the saturation value depends on the final exposure temperature and not on the thermal history of the sample. Significantly, the luminescence lifetime was found to have little dependence on the passivation temperature, having a value of $52 \pm 2 \mu \mathrm{s}$ (measured for $800 \mathrm{~nm}$ ) at saturation for samples passivated. The unpassivated samples exhibited a luminescent lifetime of $40 \mu \mathrm{s}$.

Previous studies ${ }^{4-7}$ suggested that the dominant recombination centers at planar $\mathrm{Si} / \mathrm{SiO}_{2}$ interfaces are $P_{b}$ centers. These consist of a Si dangling bond localized on a trivalently bonded $\mathrm{Si}$ bond $\left(-\mathrm{Si} \equiv \mathrm{Si}_{3}\right)$ and can be passivated by reaction with $\mathrm{H}$. The $\mathrm{H}$-passivated $P_{b}$ center $\left(\mathrm{H}-\mathrm{Si} \equiv \mathrm{Si}_{3}\right)$, denoted as $\mathrm{H} P_{b}$, can also be depassivated, giving rise to a $P_{b}$ center. As a result, the saturation of the PL intensity following passivation can be discussed within the framework of existing passivation and depassivation kinetics for planar interfaces, especially atomic $\mathrm{H}$-induced passivation and depassivation kinetics. ${ }^{5-7}$

Saturation of the PL intensity can be qualitatively explained by a steady-state balance between hydrogen passivation and depassivation of nonradiative recombination centers. Passivation of $P_{b}$ centers with $\mathrm{H}$ proceeds by the reaction $\mathrm{H}+P_{b} \rightarrow \mathrm{H} P_{b}$ and depassivation of $\mathrm{H} P_{b}$ centers can proceed via a thermal dissociation reaction $\mathrm{H}_{b} \rightarrow P_{b}+\mathrm{H}$ or, in the presence of high $\mathrm{H}$ concentrations, by the reaction $\mathrm{H}$ $+\mathrm{H} P_{b} \rightarrow P_{b}+\mathrm{H}_{2}$. These reactions can occur simultaneously 
during the passivation treatment, with previous studies suggesting that the hydrogen-induced depassivation reaction is the dominant depassivation reaction under the current experimental conditions. ${ }^{11}$ Under these assumptions the relative $P_{b}$ concentration is given by

$$
\frac{\left[P_{b}\right]}{N_{0}}=\frac{k_{d}}{k_{d}+k_{f}}+\frac{k_{f}}{k_{d}+k_{f}} \exp \left[-\left(k_{f}+k_{d}\right)(\mathrm{H}) t\right],
$$

where the $k_{f}$ and $k_{d}$ are rate constants given by the Arrhenius expressions $k_{f}=k_{f 0} \exp \left(-E_{f} / k \mathrm{~T}\right)$ and $k_{d}=k_{d 0} \exp \left(-E_{d} / k \mathrm{~T}\right)$, with $k_{f 0}$ and $k_{d 0}$ being attempt rates, $E_{f}$ and $E_{d}$ being activation energies for the passivation and depassivation reactions, $N_{0}$ is the maximum concentration of defects $\left(P_{b}+\mathrm{H} P_{b}\right)$, and $[\mathrm{H}]$ is the hydrogen concentration. As $t$ approaches infinity, $\left[P_{b}\right] / N_{0}$ approaches a limit of $k_{d} /\left(k_{d}+k_{f}\right)$. Since the PL intensity $I_{\mathrm{PL}}$ is related to the nanocrystal concentration through the relationship $I_{\mathrm{PL}}=\sigma \phi n^{*} \tau / \tau_{\text {rad }}$, where $\sigma$ is the excitation cross section, $\phi$ is the photon flux, $n^{*}$ is the number of luminescent nanocrystals, $\tau$ is the luminescence lifetime, and $\tau_{\text {rad }}$ is the radiative lifetime. It can be shown to be related to the defect concentration $\left[P_{b}\right]$ by a relationship of the form $I_{\mathrm{PL}} / \tau \sim n^{*} \sim\left(n_{\text {total }^{-}}\left[P_{b}\right]\right)$. Since in the present studies $\tau$ is approximately constant at saturation, the relative PL intensity at saturation $\mathrm{PL}_{s}$ has a form

$$
\mathrm{PL}_{s}=A\left(1-\frac{k_{d}}{k_{d}+k_{f}}\right)+1
$$

where $A$ is a proportionality constant. Assuming $E_{f}>E_{d}$, Eq. (2) yields a behavior that the saturated PL intensity increases with the increasing $\mathrm{H}$-exposing temperature as shown in Fig. 6. This fact supports the notion that saturation is due to competition between passivation and depassivation reactions, with the activation energy for the passivation reaction being larger than that for the depassivation reaction.

\section{CONCLUSIONS}

In conclusion, data have been presented for atomic $\mathrm{H}$ passivation of $\mathrm{SiO}_{2}$ films containing $\mathrm{Si}$ nanocrystals. The $\mathrm{Si}$ nanocrystals were produced by thermally annealing Si-rich oxide films. PL intensity increases with the increasing $\mathrm{H}$-passivation time, saturating at a level that depends on the $\mathrm{H}$-passivation temperature. The results demonstrate that depassivation reactions have a significant impact on the $\mathrm{H}$-passivation-enhanced PL intensity. This was shown to lead to a temperature-dependent saturation of the PL intensity. Analysis showed that this saturation was consistent with a difference in activation energies for the passivation and depassivation reactions, with the activation energy for the passivation reaction being larger than that for the depassivation reaction.

\section{ACKNOWLEDGMENTS}

This work was supported by Research Institute for Basic Science at Kangwon National University.

${ }^{1}$ L. T. Canham, Appl. Phys. Lett. 57, 1046 (1990).

${ }^{2}$ K. S. Zhuravlev, A. M. Gilinsky, and A. Yu. Kobitsky, Appl. Phys. Lett. 73, 2962 (1998).

${ }^{3}$ M. L. Reed and J. D. Plummer, J. Appl. Phys. 63, 5776 (1988).

${ }^{4}$ K. L. Brower, Phys. Rev. B 38, 9657 (1988).

${ }^{5}$ K. L. Brower and S. M. Myers, Appl. Phys. Lett. 57, 162 (1990).

${ }^{6}$ E. Cartier, J. H. Stathis, and D. A. Buchanan, Appl. Phys. Lett. 63, 1510 (1993).

${ }^{7}$ J. H. Stathis and E. Cartier, Phys. Rev. Lett. 72, 2745 (1994).

${ }^{8}$ A. Stesmans, J. Appl. Phys. 92, 1317 (2002).

${ }^{9}$ S. Cheylan and R. G. Elliman, Appl. Phys. Lett. 78, 1225 (2001).

${ }^{10}$ A. R. Wilkinson and R. G. Elliman, Appl. Phys. Lett. 83, 5512 (2003).

${ }^{11}$ A. R. Wilkinson and R. G. Elliman, Phys. Rev. B 68, 155302 (2003).

${ }^{12}$ J. P. Proot, C. Delerue, and G. Allan, Appl. Phys. Lett. 61, 1948 (1992).

${ }^{13}$ K. S. Min, K. V. Shcheglov, C. M. Yang, H. Arwater, M. L. Brongersma, and A. Polman, Appl. Phys. Lett. 69, 2033 (1996).

${ }^{14}$ L. Skuja, J. Non-Cryst. Solids 179, 51 (1994).

${ }^{15}$ T. Shimizu-Iwayama, D. E. Hole, and I. W. Boyd, J. Phys.: Condens. Matter 11, 6595 (1999). 